Federal Reserve Bank of Minneapolis

Quarterly Review

Fall 1979

Why Markets in Foreign Exchange Are Different

From Other Markets (p. l)

Is the Fed's Seasonal Borrowing Privilege Justified? (p.9)

District Conditions (p.15) 


\section{Federal Reserve Bank of Minneapolis \\ Quarterly Review vol. 3, No.4}

This publication primarily presents economic research aimed at improving policymaking by the Federal Reserve System and other governmental authorities.

Produced in the Research Department. Edited by Arthur J. Rolnick, Kathleen S. Rolfe, and Alan Struthers, Jr. Graphic design by Phil Swenson and charts drawn by Mary K. Steffenhagen, Graphic Services Department.

Address requests for additional copies to the Research Department, Federal Reserve Bank, Minneapolis, Minnesota 55480.

Articles may be reprinted if the source is credited and the Research Department is provided with copies of reprints.

The views expressed herein are those of the authors and not necessarily those of the Federal Reserve Bank of Minneapolis or the Federal Reserve System. 


\title{
Why Markets in Foreign Exchange Are Different From Other Markets*
}

\author{
Neil Wallace \\ Adviser, Research Department \\ Federal Reserve Bank of Minneapolis \\ and Professor of Economics \\ University of Minnesota
}

In the United States today, a substantial majority of economists agrees that some or all of the task of determining exchange rates should be left to private markets. The notion seems to be that basic or fundamental factors determine equilibrium relative prices of currencies - that is, exchange rates - in much the same way that tastes, technology, and endowments interact in markets to determine equilibrium relative prices for other things.

If there is any disagreement, it seems to be only about whether some government intervention is desirable in order to keep actual exchange rates close to the equilibrium exchange rates supposedly determined by fundamentals. Interventionists claim that speculation plays an important role in foreign exchange markets, one that at times prevents exchange rates from attaining even approximately their equilibrium values. Noninterventionists respond by turning my title into a challenging question. Why, they ask, are markets for foreign exchange different from other markets? Presumably, there is speculation whenever views about future prices affect current demands and supplies and, hence, current prices. Such speculation is pervasive. Can it be established that there is more speculation in foreign exchange markets than in other markets? And even if that could be established, could the desirability of government intervention depend on the amount of speculation? In the view of noninterventionists, such a conclusion runs counter to invisible-hand propositions. These depend for their validity only on general quali-

*This is a revised version of a talk presented at a seminar at the University of Minnesota. I am indebted to colleagues at the University and at the Federal Reserve Bank of Minneapolis, especially Arthur Rolnick, for helpful comments. The ideas expressed were developed jointly by John Kareken and me (1978a, b). [Author names and years refer to the works listed at the end of this paper.] tative assumptions. They do not depend on whether there is little or much speculation.

Thus, there seems to be a certain consistency in the view of noninterventionists. If currencies are very much like other things, then why, indeed, not let private markets determine their relative prices? But today's currencies are not like other things. Because of this, the noninterventionist view is fallacious - and more seriously flawed than even interventionists have suggested.

The objects traded in today's foreign exchange markets are fiat currencies. In particular, currencies now are not tied to different weights of gold or other metals. Economists have long known and agreed that fiat currencies are very special objects, not at all like other things. What they seem not to have recognized is that this specialness tells us why markets in foreign exchange are different, qualitatively, from other markets.

For fiat currencies, there are no inherent fundamentals that determine equilibrium exchange rates. Without binding legal restrictions on asset holdings that prevent one currency from being substituted for another either directly or indirectly via international borrowing and lending, demands for different currencies are determined not in part by speculation, but entirely by speculation. One consequence is an indeterminacy proposition: Without government intervention in foreign exchange markets and without binding restrictions on currency holdings, exchange rates, price levels, and in general all prices are indeterminate. A closely related consequence is that the fixed rate-floating rate dichotomy is inadequate both for descriptive analysis and for policy analysis. When exchange rates are not fixed, a crucial role is played either by legal restrictions on asset holdings or by anticipated govern- 
ment intervention. These are the only forces that determine exchange rates when rates are not explicitly fixed, and these are not comparable to the fundamentals that determine prices in other markets. A so-called laissez-faire floating rate monetary system does not give rise to a determinate equilibrium, let alone to one to which invisible-hand conclusions apply.

These assertions follow from postulates about fiat currencies. As we will see, these postulates and their implications make clear why one goes badly astray by reasoning about the international monetary system from an analogy between fiat currencies and other objects like apples, oranges, and shares in General Motors.

\section{Postulates: The Nature of Fiat Currencies}

I will take as postulates three generally accepted properties of any fiat currency:

1. It is intrinsically useless.

2. It is unbacked.

3 . It is costless to produce.

The first postulate says that a fiat currency is never wanted for its own sake. One person gives up goods-leisure or other objects that are wanted per se - for some amount of the fiat currency only because the person expects to be able subsequently to exchange the currency for goods. Put somewhat differently, this postulate says that there is only an indirect or derived demand for fiat currency; it is wanted only to the extent that it makes possible future consumption.

The second postulate says that the issuer of a fiat currency does not promise to exchange it for any other object. From the point of view of the issuer, a unit of fiat currency is a claim on no more than a fresh piece of the same thing. As has always been recognized, it is this postulate that distinguishes fiat money from commodity money and from other assets like shares in General Motors; the issuer of a fiat currency does not promise to pay the bearer now or in the future an amount of gold or a dividend or anything else.

The third postulate is simply a convenient way to express the idea that a fiat currency is an object whose value in exchange exceeds the marginal cost of producing another unit of it.

These postulates cast doubt on the analogy that advocates of floating rates use to support their view: Since private markets can price apples in terms of oranges, they can price one currency in terms of another. Neither apples nor oranges nor shares in General Motors satisfy the above postulates.

\section{Supplies of Fiat Currencies}

The second and third postulates - that fiat currency is unbacked and is costless to produce-have wellknown and almost unanimously accepted implications for the provision or supply of fiat currencies: Their provision cannot be left to the market. More precisely, one cannot allow for free entry into the provision of fiat currency. Indeed, leading advocates of floating exchange rates, such as Milton Friedman, have long espoused this view:

Some external limit must be placed on the volume of a fiduciary [that is, fiat] currency in order to maintain its value. Competition does not provide an effective limit, since the value of the promise to pay, if the currency is to remain fiduciary, must be kept higher than the cost of producing additional units. The production of a fiduciary currency is, as it were, a technical monopoly, and hence, there is no such presumption in favor of the private market as there is when competition is feasible. ${ }^{1}$

This widely accepted implication for the supplies of fiat currencies makes clear that the analogy between fiat currencies and other things is far from complete. For most objects, supplies and demands can be determined in a free market, one in which neither supply nor demand is regulated. For fiat currencies, most economists agree that supplies must be regulated and that, at most, demands can be left unregulated.

\section{Demands for Fiat Currencies}

The United States has recently issued a new coin: the Susan B. Anthony dollar. The sense in which freemarket or unregulated demands for fiat currencies are determined entirely by speculation can be seen by considering how the market would price Anthonys in terms, say, of Lincolns ( $\$ 5$ bills) in different circumstances.

Suppose that an Anthony had no numeral on it, just a picture. If the government says that now and in the future it stands ready to exchange five Anthonys for one Lincoln and vice versa, then the Anthony becomes a "one," even though there is no numeral on

\footnotetext{
${ }^{1}$ Friedman 1960, p. 7.
} 
it. Suppose, instead, that there are fixed stocks of Anthonys and Lincolns outstanding today and that the government says that starting in June 1980 and thereafter it will exchange five Anthonys for one Lincoln and vice versa. Will five Anthonys still exchange for one Lincoln? Our postulates dictate an affirmative answer. If not, then the rates of return from now until June 1980 on Lincolns and Anthonys would have to differ, and that would violate the first fiat currency postulate - that currency is intrinsically useless. In other words, the announced future exchange ratio is today's market exchange ratio. And, so long as the announcement is believed, it does not matter whether the date at which exchanges are offered is June 1980, June 1982, or June 1988.

This is not true for apples and oranges, or for shares in GM and shares in Chrysler. While the government could readily make effective any exchange ratio between Anthonys and Lincolns, it would have some trouble doing that for apples and oranges or for shares in GM and shares in Chrysler. Even if that difficulty is ignored, the future exchange ratio is only one of the influences on the current relative price of the fruits or the shares. For apples and oranges, the influence of the future exchange rate is limited by the fact that apples and oranges are wanted per se, for eating and so forth. For shares in GM and shares in Chrysler, its influence is limited by the fact that there are dividend streams. For Anthonys and Lincolns, there are no such fundamentals to help determine the current relative price.

The most startling difference between Anthonys and Lincolns, on the one hand, and the fruits or the shares, on the other hand, is what happens when no future exchange ratio is announced. In the case of apples and oranges or of shares in GM and shares in Chrysler, a current exchange ratio is determined without any government help. But what about Anthonys and Lincolns? For simplicity, suppose that there are fixed and unchanging quantities of the two. Even in this simple case, it is absurd to suppose that fundamental factors could guide the market to find an equilibrium exchange rate. Is it less absurd to suppose that an unfettered market could find an exchange rate between German marks and Lincolns?

That it is no less absurd is the content of the indeterminacy proposition to which we now turn. That proposition explains why a floating rate system with unregulated demands for fiat currencies is, to put it mildly, unworkable.

\section{Indeterminacy Under Laissez-Faire Floating Rates}

For simplicity, let there be two countries and two currencies, the supplies of which at time $t$ are given and denoted by $M_{1}(t)$ and $M_{2}(t)$. (As the reader will see, the generalization to any number of countries and currencies is trivial.) I will argue that in the absence of government intervention in exchange markets and in the absence of legal restrictions on asset holdings - for example, restrictions on who may hold and use what currency - there is indeterminacy. I will do this by arguing that if there is an equilibrium for any positive and unchanging exchange rate, then there is an equilibrium for any other positive and unchanging exchange rate.

Given the paths of the individual currencies, we may define a world currency supply, denoted $M(t)$, by $M(t)=M_{1}(t)+R M_{2}(t)$, where $R$ is some positive and unchanging exchange rate. Clearly, then, different values of $R$ imply different paths of the world currency supply, $M(t)$. The argument that any of these paths generates an equilibrium if any one of them does has two ingredients. First, any unchanging exchange rate, $R$, and our second postulate imply that the rate of return on one currency is equal to the rate of return on the other in every period. Second, although different values of $R$ imply different paths of the world currency supply, these paths are similar in one crucial respect. For a wide class of supply paths for the individual currencies, the limiting growth rate of the world currency supply, $M(t)$, does not depend on $R$. While this similarity is enough to yield the indeterminacy result in many complete models, the essential ideas are brought out by considering the simple case where the individual currency supplies are constant over time.

If the supplies of the individual currencies are constant over time, then different values of $R$ imply different unchanging world currency supplies. In this case, the indeterminacy proposition is simply that if there is an equilibrium for one currency supply, then there is also an equilibrium for any other currency supply. Again, we may quote Friedman:

[The provision of fiat currency] is a monopoly that so far as I know has a unique property - the total value to the community of the stock of the monop- 
oly product is entirely independent of the number of units in the stock. For any other item entering into economic exchange that I can think of, be it shoes or hats or tables or houses or even honorific titles, the aggregate value of the stock in terms of other goods depends on the number of units in it, at least outside some limits. For money, it does not. If there are five million pieces of paper, or five thousand, or five hundred million, as long as the number is relatively stable, the aggregate value is the same; the only effect is that each unit separately has a smaller or larger value as the case may be; that is, prices expressed in terms of the money are higher or lower. ${ }^{2}$

But this argument may not seem sufficient. Although different exchange rates imply different world currency supplies, they also imply different compositions of it. The larger is $R$, the greater is the fraction of the world currency supply that takes the form of currency issued by country two. If the indeterminacy proposition is correct, then that fraction can be anything. In particular, for large enough $R$, everyone in the world - both residents of country one and residents of country two-use the currency of country two almost exclusively, while for small enough $R$, the reverse is true. Can this really be?

Why not? First, recall that the rates of return on the two currencies are the same. Second, by hypothesis, no legal restrictions prevent residents of one country from using the currency of another. In these circumstances, why would residents of country one prefer their own national currency and residents of country two prefer theirs? Could it be because residents of a particular country prefer the color of or the pictorial design on the currency of their own country? Such preferences violate the postulate that currency is intrinsically useless and, moreover, seem silly.

Without legal restrictions, there is no reason why national borders should determine currency usage. Canadian dollars have long circulated in areas of the United States that border Canada. That being so, one can imagine a much larger use of Canadian currency in the United States. For another example, the Bank of America recently wanted to offer deposits denominated in Japanese currency but was officially discouraged. Suppose that this quasi-legal restriction had not been imposed. One could then well imagine that Japanese currency would circulate in California. And, if in
California, why not in Nevada and Arizona? Or, to take another example, without legal restrictions, can't one imagine United States dollars circulating widely in Mexico? If questions like these are answered affirmatively, as I think they must be, then the fraction of the world money supply in a particular form can be anything. This implies that the exchange rate is indeterminate. Moreover, if the exchange rate is indeterminate, then so is the distribution of wealth and, hence, in general all prices. ${ }^{3}$

But what should we make of this indeterminacy proposition? How do we reconcile it with observations on historical episodes in which exchange rates have floated? And how do we account for the observation that national borders do, in large measure, determine currency usage? Moreover, if we accept the indeterminacy proposition, what are its policy implications? There is, I think, a single route to answers to these questions. The indeterminacy proposition is based on hypotheses that specify an absence of government intervention in exchange markets and/or specify an absence of legal restrictions on asset holdings. At least some of these hypotheses must be abandoned.

\section{Non-Laissez-Faire Floating Rate Systems}

Economists have, by and large, approached the positive analysis of international monetary arrangements in terms of a dichotomy: fixed exchange rates or floating exchange rates. The indeterminacy proposition, however, says that the floating rate regime is not welldefined without legal restrictions on asset holdings or government intervention. It suggests the following approach. When analyzing any situation in which exchange rates are not fixed explicitly, try to identify the less obvious forms of intervention in exchange markets and/or the restrictions on asset holdings that could produce a determinate equilibrium.

One less obvious form of intervention in foreign exchange markets was hinted at above. Anticipated intervention can play much the same role as actual intervention.

\footnotetext{
${ }^{2}$ Friedman 1960, p. 7

${ }^{3}$ For a formal argument and one that establishes the existence of equilibria of this sort for constant and nonconstant paths of the individual currency supplies, see Kareken and Wallace 1978a. By the way, it is not evident that only constant exchange rate paths can be equilibria. I suspect, but have not yet shown, that any member of a wide class of random exchange rate paths also qualifies as an equilibrium.
} 
Two widely cited episodes of so-called floating exchange rates are the post-Civil War period in the United States when "greenbacks" were not officially tied to gold, and the post-World War I period when the British pound was not officially tied to gold. One common feature of both episodes is that gold convertibility was subsequently restored. That being so, it seems farfetched to analyze those episodes as if people thought at the time that gold convertibility would never be restored. Therefore, for these episodes, probable future restoration of gold convertibility is a form of government intervention that constitutes a departure from the hypotheses that produce indeterminacy. ${ }^{4}$

For today's currencies, restoration of convertibility into a commodity seems farfetched. But it is not unreasonable to say that post-World War II floating rate episodes have been accompanied by anticipated intervention if exchange rates wandered too far-too far, perhaps, from those that would have prevailed under pervasive controls on asset holdings. The intervention may be exchange market intervention by countries acting cooperatively or may involve the imposition of restrictions on asset holdings which makes feasible intervention by a country acting alone. Thus, for example, from this point of view, it is reasonable to explain the behavior of the U.S. dollar in exchange markets over the period August 1971 to November 1978 in terms of the U.S. government, with the implicit agreement of other countries, "talking down" the value of the dollar. It is also understandable that some market participants expressed doubts about how much had been accomplished in November 1978 because the U.S. did not impose restrictions on asset holdings.

In fact, today the most obvious and important departures from the hypotheses yielding indeterminacy are actual or threatened restrictions on capital-account transactions. Such restrictions tend to prevent one currency from being substituted for another, both directly and indirectly by way of international borrowing and lending. To the extent that this is accomplished, the indeterminacy disappears.

There are many instances of actual restrictions on asset holdings. (In the case of Israel, both the controls on asset holdings and their partial removal in 1977 have been widely commented on, if not completely understood.) Instances of threatened restrictions are harder to identify, but can play much the same role as actual restrictions. Thus, suppose that the equilibrium exchange rate between $M_{1}$ and $M_{2}$ would be $\bar{R}$ in the presence of pervasive capital controls, and suppose that it is anticipated that any sizable departure of the actual exchange rate from $\bar{R}$ will trigger the imposition of pervasive controls. Then, it can be shown that the exchange rate stays close to $\bar{R} .^{5}$

There is, moreover, a close relationship between the role of controls on asset holdings in producing determinate exchange rates and the notion that equilibrium exchange rates are determined by the condition that trade be balanced. In order to understand this relationship, it is helpful to begin with what economists call the barter theory of trade, that part of trade theory which analyzes economic connections among countries in models that do not contain currencies or, therefore, exchange rates.

It is, by now, well known that trade can be out of balance, even permanently, in such barter or nonmonetary models. Essentially, imbalance of trade is accompanied by residents of one country being net creditors or debtors to residents of other countries, or, what amounts to the same thing, by residents of one country owning on net more or less than all the assets located in their own country. ${ }^{6}$ In these nonmonetary models, one way to insure trade balance is to rule out by law any capital-account transactions, any net borrowing between residents of one country and residents of other countries, and any ownership of assets not located in the country of residence. As a matter of accounting, such a prohibition implies trade balance.

Now consider a model in which there is a role for currency, a model in which there is a demand for currency. Again, as a matter of accounting, the imposition of laws that preclude capital-account transactions - and, hence, the ownership by residents of one country of currency issued by other countries - implies trade balance. It also, as suggested above, implies a well-defined demand for the currency issued by the

\footnotetext{
${ }^{4}$ Alternatively, one may say that "greenbacks" and post-World War I British pounds were not fiat currencies: they violate the second postulate. They should be treated as discount bonds that were in (partial) default; holders were uncertain both about the date at which each would pay off in terms of gold and about the amount of the payoff.

${ }^{5}$ For explicit analyses of policy schemes that specify contingent and possibly random future intervention and asset-holding restrictions, see Kareken and Wallace 1978a and Nickelsburg forthcoming.

${ }^{6}$ See Gale 1971, 1974 and Kareken and Wallace 1977.
} 
home country and, hence, a determinate exchange rate. But the result that pervasive capital controls implies both trade balance and a determinate exchange rate is quite different from the fallacious notion that trade balance is a natural state of affairs and that an equilibrium exchange rate is determined by the condition that trade be balanced.

Many readers, I suspect, will argue that this discussion overemphasizes restrictions on asset holdings like capital controls at the expense of more subtle restrictions like those implied by legal-tender laws. While these readers may concede that only legal, nonlaissez-faire restrictions create well-behaved demands for individual currencies, they might assert, first, that restrictions like legal-tender laws do produce such demands, and second, that such restrictions are in effect in all countries at all times. That being so, they might claim, one is justified in simply assuming that there are well-behaved demands for individual currencies, whether or not more explicit restrictions like capital controls are in effect. I am doubtful.

First, the pervasiveness of legal-tender laws has not seemed to prevent the occurrence of hyperinflations during which the fraction of wealth held in the form of a particular currency has approached zero. Second, an explicit analysis of legal-tender laws - which, by the way, would have to recognize that they amount to explicit restrictions like a requirement that real tax liabilities be paid in the form of a particular currency would suggest that such laws at best imply lower bounds on the amount of wealth held in the form of a particular currency. So long as the total demand for currency in each country exceeds the lower bound implied by the country's legal-tender laws, the absence of other asset restrictions or intervention implies a range of indeterminacy. That the indeterminacy range is large is suggested by the fact that most countries have at times found it necessary to resort to more explicit restrictions on asset holdings. A large indeterminacy range is also consistent with the behavior of exchange rates and money supplies in many countries during the last few years. That behavior cannot be easily interpreted in terms of well-behaved demand functions for individual currencies.

\section{Policy Options in a World of Many Fiat Currencies}

Noninterventionist advocates of floating rates have painted a rosy picture of floating exchange rates.
Milton Friedman, for instance, asserts that a floating rate system can be as free of capital-account and trade restrictions as a single currency system:

The basic fact is that a unified currency and a system of freely floating exchange rates are members of the same species even though superficially they appear very different. Both are free market mechanisms for interregional or international payments. Both permit exchange rates to move freely. Both exclude any administrative or political intermediary in payments between residents of different areas. Either is consistent with free trade between areas, or with a lessening of trade restrictions. ${ }^{7}$

Unfortunately, the picture is a mirage. Friedman's claims about freely floating exchange rates rest on the notion that without legal restrictions of various kinds the demands for individual currencies are well behaved. That view, in turn, rests on no more than an analogy between currencies and other objects, an analogy that we have seen to be faulty. Since freely floating exchange rates imply indeterminacy, such an international monetary system is not an option. The alternatives to fixed exchange rates are various kinds of implicit intervention schemes and implicit or explicit restrictions on asset holdings.

That these are the options follows from the properties of fiat currency described above, in particular, that fiat currency is intrinsically useless and unbacked. The formation of the European Monetary Union is consistent with these properties. The predominant view in the United States about feasible international monetary systems is not.

Unfortunately, none of the feasible options is without drawbacks. As is widely understood, a system of cooperatively fixed exchange rates requires that national control over currency issue be surrendered. In essence, it requires that countries coordinate the degree to which they tax by inflation or, in other words, the degree to which they finance current expenditures with permanent additions to indebtedness. The alternatives, though, are also unpleasant. They involve the imposition of controls on the kinds of assets individuals can hold.

It is becoming widely recognized that the value of

\footnotetext{
${ }^{7}$ Friedman 1968 , p. 7.
} 
the U.S. dollar in terms of goods and its value in terms of other currencies are closely related. It is also widely recognized that domestic policies in the United States - essentially, the degree to which we resort to taxation by permanent increases in indebtedness - must be brought into line with that of other countries if the U.S. dollar is to have a stable value in terms of other currencies. What is not widely recognized is that coordination of budget policies in this sense is only one of the conditions needed to stabilize both the goods value and the foreign currency value of the U.S. dollar. Without intervention in exchange markets or restrictions on asset holdings, indeterminacy prevails. That being so, we should at least consider pursuing an explicit policy directed toward cooperative and permanent exchange market intervention or toward controls on asset holdings. The alternative is to leave market participants guessing or speculating about future actions of these kinds.

\section{References}

Friedman, Milton. 1960. A program for monetary stability. New York: Fordham University Press.

1968. Dollars and deficits. Englewood Cliffs, N.J.: Prentice-Hall.

Gale, David. 1971. General equilibrium with imbalance of trade. Journal of International Economics 1 (May): 141-58.

1974. The trade imbalance story. Journal of International Economics 4 (May): 119-37.

Kareken, John, and Wallace, Neil. 1977. Portfolio autarky: a welfare analysis. Journal of International Economics 7 (February): 19-43.

1978a. Samuelson's consumption-loan model with countryspecific fiat monies. Research Department Staff Report 24. Federal Reserve Bank of Minneapolis, Minnesota.

1978b. International monetary reform: the feasible alternatives. Federal Reserve Bank of Minneapolis Quarterly Review 2 (Summer): $2-7$.

Nickelsburg, Gerald. Forthcoming. Flexible exchange rates and uncertain government policy: a theoretical and empirical analysis. Ph.D. dissertation. University of Minnesota. 